\title{
Experimental silicosis does not aggravate collagen-induced arthritis in mice
}

\author{
Robby Engelmann ${ }^{*}$ and Brigitte Müller-Hilke
}

\begin{abstract}
Objectives: To investigate the effect of chronic lung inflammation on the incidence and severity of collageninduced arthritis in mice.

Methods: Chronic lung inflammation in the form of silicosis was induced via intranasal application of silica particles. Immunization with collagen Type II commenced one week later and mice were sacrificed six weeks after booster immunization. Thereafter, silicosis was confirmed via flow cytometry and arthritis was evaluated performing knee and paw histology.

Results: Pronounced lung inflammation in the silica-treated compared to PBS-treated control mice was demonstrated by significantly elevated broncho-alveolar lavage (BAL) cell count, attributable to increased numbers of macrophages and granulocytes. Inflammation in the lungs was not associated with elevated PAD2 and PAD4 expression, yet silica treated animals had significantly higher aCCP serum titers. However, lung inflammation did not lead to an increase in the incidence of arthritis, nor did it exacerbate the macroscopic or histologic joint scores.
\end{abstract}

Conclusions: Chronic lung inflammation resulting from silicosis does not aggravate collagen-induced arthritis in mice.

Keywords: Mucosal immunity, Collagen-induced arthritis, Silicosis

\section{Background}

Rheumatoid arthritis (RA) is a systemic autoimmune disease which manifests predominantly as a chronic polyarthritis. The autoantibodies against citrullinated antigens (ACPA) have become indispensable for RA diagnosis and define a distinct subset of RA for which a variety of genetic and environmental risk factors have been described. While the strongest genetic risk is conferred by genes encoding the major histocompatibility complex (HLA), environmental risk factors include smoking, exposure to silica particles and air pollution as well as periodontitis and the recently discussed gastrointestinal microbiota $[1,2]$.

Among these, smoking is the most extensively studied risk factor for RA. It predisposes for ACPA-positive RA in subjects carrying the shared HLA epitope [3]. Not only the expression of the citrullinating enzyme peptidylarginine deiminase (PAD) 2 but also citrullinated

\footnotetext{
* Correspondence: robby.engelmann@med.uni-rostock.de Institute of Immunology \& Core Facility for Cell Sorting \& Cell Analysis,

Rostock University Medical Center, Schillingallee 70, 18057 Rostock, Germany
}

proteins are elevated in the lungs of smokers compared to non-smokers [4]. These findings suggested that smoking causes an increase in citrullination which eventually leads to the breach in tolerance. However, a recent report demonstrated that it is not the cigarette smoke per se that increases citrullination in the lungs. In fact, it appears that it is inflammation associated with smoking that is responsible for elevated levels of citrullinated lung proteins as the latter were also demonstrated for patients with chronic obstructive pulmonary disease (COPD) [5]. We therefore set out to investigate the effect of silicosis a model for chronic lung inflammation - on collageninduced arthritis, a murine model for RA.

\section{Methods \\ Mice \\ Female DBA/1J (Charles River, Wilmington, MA, USA) and male B10.q (Jackson) mice were crossed. Parental and F1 mice were maintained in a specific pathogen free unit on a $12 \mathrm{~h}$ light $/ 12 \mathrm{~h}$ dark cycle with $30 \mathrm{~min}$ twilight period. The ambient temperature was $21 \pm 2^{\circ} \mathrm{C}$, the}


humidity was $60 \pm 10 \%$ and the room air change is 20 fold. Mice were housed using a stocking density of 3-5 mice per cage. Mice were given water and ssniff $\mathrm{R} / \mathrm{M}-\mathrm{H}$ diet (ssniff Spezialdiäten $\mathrm{GmbH}$, Soest, Germany) ad libitum.

\section{Silicosis}

A solution of $40 \mathrm{mg}$ silica particles [particle size range: 0.5-10 $\mu \mathrm{m}, 80 \%$ are 1-5 $\mu \mathrm{m}$ ] (Sigma Aldrich, St. Louis, MO, USA) per ml PBS was prepared and sonicated for $10 \mathrm{~min}$ prior to use. Male F1 mice aged 6-12 weeks were anesthetized by i.p. injection of $75 \mathrm{mg} / \mathrm{kg}$ ketamine (bela-pharm GmbH \& Co. KG, Vechta, Germany) and $6 \mathrm{mg} / \mathrm{kg}$ xylazine (Bayer AG, Leverkusen, Germany). Two droplets of $15 \mu$ l of silica solution each were subsequently applied onto the noses of the anesthetized animals. Controls were given the same amount of PBS alone. The suspension was inhaled involuntarily and mice developed pulmonary inflammation as described previously [6].

\section{Collagen-induced arthritis}

Collagen-induced arthritis was induced one week after intranasal treatment with silica particles or PBS. Bovine collagen type II (MD Bioscience, St. Paul, MN, USA) was dissolved at a concentration of $2 \mathrm{mg} / \mathrm{ml}$ in sterile $0.1 \mathrm{M}$ acetic acid by stiring overnight at $4^{\circ} \mathrm{C}$. Complete Freunds' adjuvant (CFA) was prepared by thoroughly mixing $25 \mathrm{ml}$ incomplete Freunds' adjuvant (IFA) (Difco, Detroit, MI, USA) with $100 \mathrm{mg}$ M. tuberculosis H37 RA (Difco, Detroit, MI, USA). For the primary immunization $400 \mu \mathrm{l}$ CFA was mixed with $400 \mu \mathrm{l}$ collagen solution and $100 \mu \mathrm{l} /$ mouse were injected intradermally at the tail base. Booster immunization was performed 3 weeks after primary immunization using IFA instead of CFA. Mice were scored weekly, following an extended scoring protocol whereby each paw was scored for macroscopic signs of arthritis. Each affected distal joint of the toe/knuckle scored one point and affected midpaws/ankles scored five points. Thus, each paw can reach a maximum score of 15 and each mouse a maximum score of 60 .

\section{Evaluation of silicosis}

Six weeks after booster immunization, animals were anesthetized and broncho-alveolar lavage cells were isolated by flushing the lungs 3 times with $800 \mu \mathrm{l}$ PBS pH 7.4 containing $0.1 \mathrm{mM}$ EDTA. Collected cells were counted in a hemocytometer and subsequently centrifuged at $300 \times \mathrm{g}$ for $10 \mathrm{~min}$. Cell pellets were then resuspended in $100 \mu \mathrm{l}$ ice-cold PBS pH 7.4, 0.5\% bovine serum albumin, $0.1 \%$ sodium azide and therein stained for CD11c: FITC (clone HL3, BD, Franklin Lakes, NJ, USA), CD45:PE (clone 30-F11, Biolegend, San Diego,
CA, USA), GR-1: PECy7 (clone RB6-8C5, Biolegend, San Diego, CA, USA) and IA ${ }^{\mathrm{q}}$ : Alexa647 (clone KH116, Biolegend, San Diego, CA, USA). Cells were analyzed in a BD FACS Calibur (BD, Franklin Lakes, NJ, USA).

\section{Histology}

Paws and knees were excised and fixed in $4 \%$ paraformaldehyde for 5 days. Paraformaldehyde was removed under floating tap water for $30 \mathrm{~min}$ and tissues were transferred into USEDECALC (Medite GmbH, Burgdorf, Germany) for decalcification for 5 days (knees) or 2 weeks (paws). Tissue samples were paraffin-embedded and $5 \mu \mathrm{m}$ thin-sections were made. Sections were deparaffinized and rehydrated prior to staining with haematoxylin/eosin. Stained sections were scored on an Axioplan 2 microscope (Carl Zeiss AG, Oberkochen, Germany) using a previously published scoring system [7]. In brief, knee joints we scored for inflammation (evaluating the degree of infiltration yielding a score between 0 and 3), cartilage destruction (normal via empty lacunae up to complete loss of articular cartilage, again yielding a score between 0 and 3 ) and bone loss (yielding scores between 0 and 5 ). The total of all three parameters will result in a maximum score of 11 . The paws were graded differently and for the parameters pannus severity, cellular infiltration, cartilage destruction and bone loss, each yielding a score between 0 and 4 . Each paw could thus reach a maximum score of 16 and all four paws per mouse were averaged.

\section{Serum antibodies}

ACPA IgG levels were measured by combining CCP(Euroimmun, Lübeck, Germany; CCP2) and MCV(Orgentec, Mainz, Germany) coated ELISA plates with an anti-mouse IgG antibody coupled to horse radish peroxidase (STAR13B; Bio-Rad Laboratories, Hercules, CA, USA). The sera were applied at a dilution of 1:50 for $1 \mathrm{~h}$ at RT. Thereafter, the plates were incubated with the detection antibody at a dilution of 1:1000 for $1 \mathrm{~h}$. Finally, color reaction was performed using TMB substrate (Biolegend, Fell, Germany) and the optical densities were determined by an automated plate reader (Millenia Kinetic Analyser, DPC, USA). Antibody serum levels against collagen type II were analyzed by coating Nunc MediSorp ELISA plates (Thermo Fisher Scientific, Waltham, MA, USA) with bovine collagen type II (MD Bioscience, St. Paul, MN, USA) at $20 \mu \mathrm{g} / \mathrm{ml}$ in carbonate/ bicarbonate buffer overnight at $4^{\circ} \mathrm{C}$. Sera were applied at a dilution of 1:12,000 for $1.5 \mathrm{~h}$ at RT and bound antibodies were detected as described for ACPA detection.

\section{Statistics}

For normal distributed data means and SEM are shown. Otherwise medians and quartiles are used. Means were 
compared by Student's $t$-test and medians were compared by Mann Whitney $U$-test. $P$-values for the time course of CIA were calculated either by Fisher Test (incidence) or by Mann-Whitney $U$-Test (macroscopic score) for each time point separately. Statistics were performed using $\mathrm{R}$ (v3.2.2).

\section{Results}

Intranasal application of silica particles in mice led to a longstanding inflammation. The broncho-alveolar lavage (BAL) of silica treated and control mice was analyzed ten weeks after the induction of silicosis and indeed, there was a significant increase in the total numbers of BAL cells $(p<0.001)$, in particular macrophages $(p=0.03)$ and granulocytes $(p<0.001)$ after silica-treatment (Fig. 1a). Despite the longstanding inflammation, we could not detect a difference in the expression of PAD2 and PAD4 between silica treated and PBS treated mice (Additional file 1: Figure S1).
In contrast, silicosis had no impact on the incidence and severity of collagen induced arthritis. Primary immunization with collagen commenced one week after silica treatment and mice were then followed up for the rest of the observation period. At the final time point, six weeks after booster immunization, there were no differences between the silicosis and the control groups with respect to arthritis incidence and severity, the latter being scored macroscopically as well as histologically for knees and paws (Fig. 1b, c, histology is exemplified in Fig. 1d). Likewise, there was no correlation between the numbers of total BAL cells, BAL macrophages or BAL granulocytes and the macroscopic arthritis score (Additional file 1: Figure S1, data not shown) nor did we find significant differences in anti-collagen type II and anti-MCV IgG serum level comparing silica treated and PBS treated mice. However, we did find significant difference between silica treated and PBS treated mice for anti-CCP IgG serum level $(p=0.02$;
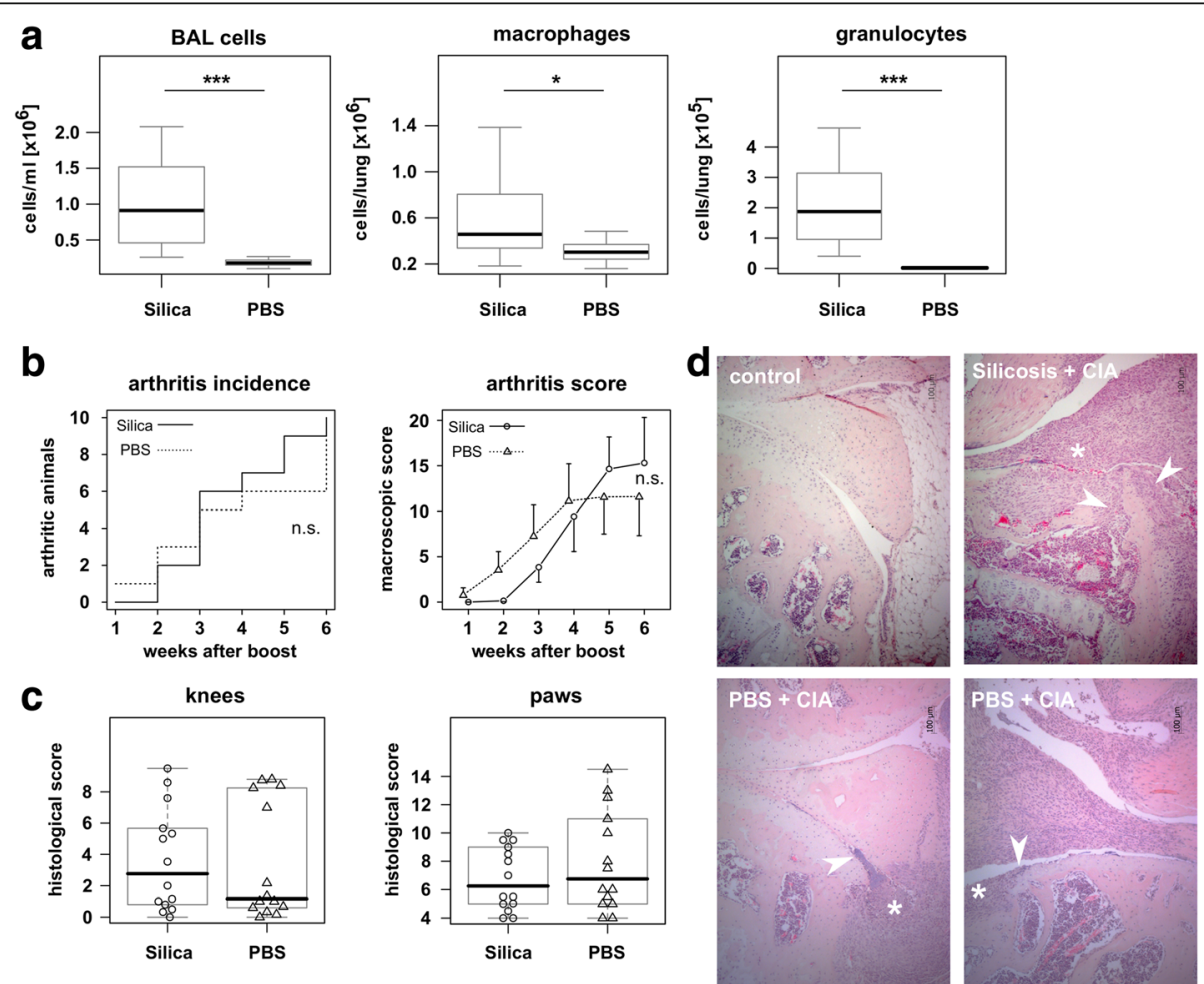

Fig. 1 Silicosis does not aggravate collagen-induced arthritis. a BAL cells from mice six weeks after booster immunization with collagen type II were isolated and phenotyped by flow cytometry for macrophages $\left(C D 45^{+} \mid A^{+} q^{+} G R-1^{-} C D 11 c^{+}\right)$and granulocytes $\left(C D 45^{+} \mid A q^{-} G R-1^{+} C D 11 c^{-}\right)$. Boxes show medians and quartiles, $p$-values were calculated by Mann-Whitney U-test. $n=14$. $\mathbf{b}$ Neither the arthritis incidence (left panel) nor the macroscopic arthritis score (right panel) differ between silica-treated and control mice. $p$-values were calculated by Fisher Test (incidence) and Mann-Whitney U-Test (macroscopic score) for each time point. c Histological scores for knee joints and paws do not differ between silica-treated and control mice. Boxes show median and quartiles, each dot represents one mouse. P-values were calculated by Mann-Whitney U-Test. d Examples for the H\&E staining of thin-sections from femorotibial joints in control mice without immunization with collagen type II (upper left panel), silicatreated mice immunized with collagen type II (upper right panel) and PBS-treated mice immunized with collagen type II (lower panels) showing a high (lower right panel) or a low (lower left panel) histological score are shown. Asterisks indicate inflammatory infiltrates. Arrowheads point at sites of cartilage or bone destruction 
Additional file 1: Figure S1) and we also found a significant correlation between anti-collagen type II IgG and the macroscopic arthritis score $(\mathrm{R}=0.65, p<0.001)$. We therefore conclude that silica induced chronic lung inflammation in the mouse does not aggravate collagen induced arthritis.

\section{Discussion}

Over the last years, studies accumulated on the genetic and environmental risk factors for RA and on factors driving the disease. Nevertheless, it is still unclear where and by which mechanisms the first break of tolerance occurs [8]. The mucosal surfaces and mucosa associated lymphoid tissues (MALT) are likely to play critical roles as the most prominent risk factors for RA - smoking, periodontitis, gastrointestinal microbiota and silicosis affect mucosal immunity. We therefore made use of a murine silicosis model to induce a chronic lung inflammation. Despite this chronic inflammatory reaction in the lungs we did not see an exacerbation of the CIA. However, this may be due to the timing between silicosis induction and CIA induction. We decided for a one week interval between silicosis induction and primary immunization with collagen in order to ensure that a full blown inflammation has been established. At five weeks after silicosis treatment - which corresponds to one week after the booster immunization - arthritis starts to be macroscopically visible and silicosis is in its chronic phase. Indeed, it has previously been shown that inflammatory markers increased already one day after the treatment with silica particles, peaking at 5 days and lasting up to 60 days with fibrosis evident at 15 days after silicosis induction [9-11]. Thus, our protocol covers all phases of silicosis.

It is unknown which factors influence the interaction between silicosis and arthritis. However, it has been described that silica treatment induces apoptosis in macrophages, which in turn increase citrullination due to elevated intracellular calcium concentrations $[4,12]$. An increase in citrullination may aggravate arthritis as described for the administration of citrullinated collagen [13]. On the other side, it is known that silica treatment can recruit $\mathrm{CD} 4$ + Foxp3+ regulatory $\mathrm{T}$ cells to the lungs which may counteract immune activation [14]. Although we did not find increased PAD2/4 expression levels in the lungs after silica treatment an increase in intracellular calcium levels would still lead to citrullination by PAD enzymes which is in line with slightly elevated antiCCP levels in our silica treated mice. However, these differences did not influence the severity of arthritis.

For the induction of CIA male sex and the major histocompatibility allel $\mathrm{A}^{\mathrm{q}}$ are crucial factors, which are all met in our model [15-17]. Likewise, complex interactions between genetics and the immune system hold true for the development of silicosis $[18,19]$. Thus, by focusing on a mouse strain that is highly susceptible for CIA we may have missed factors that are essential for an interaction between silicosis and arthritis. Furthermore, we cannot rule out that a specific activation of patternrecognition receptors contributes to CIA development yet is lacking from silicosis under specific pathogen free conditions.

\section{Conclusions}

In summary our results suggest that factors other than chronic inflammation in mucosal environments are necessary to compromise immune tolerance in the murine model of CIA. Such factors may well include genetic polymorphisms as previously shown for the geneenvironment interaction between the HLA shared epitope and smoking in human ACPA-positive RA [3].

\section{Additional files}

\begin{abstract}
Additional file 1: Figure 2. Additional information. (A) Before we did the combination of silicosis and CIA we performed a time course experiment with silicosis induction only. Eight weeks after silica or PBS treatment we sacrificed the mice and analyzed the mRNA expression of PAD2 and PAD4 in lung tissue. We did not find significant differences between the treatment and control groups nor during the time course of silicosis. (B) H\&E stainings of the lung exemplify healthy tissue (upper panel) in PBS treated mice and lung tissue with ongoing inflammation (asterisk, lower panel) in silica treated mice. (C) Serum lgG antibody levels against mutated citrullinated vimentin (MCV), cyclic-citrullinated peptides (CCP) and collagen type II (Col2) show significantly higher levels of antiCCP IgG among silica treated mice as compared to PBS treated mice (same animals as in Fig. 1). There is no difference between both groups for anti-MCV and anti-Col2 lgG. (D) No correlation exists between the number of BAL granulocytes and the macroscopic arthritis score. Spearman correlation ( $R=0.22, p=0.3$ ). However, anti-Col2 lgG levels are significantly correlated with the macroscopic arthritis score. Spearman correlation $(R=0.65, p<0.001)$ (same animals as in Fig. 1). (TIFF $2253 \mathrm{~kb}$ )

Additional file 2: Original data. (CSV $5 \mathrm{~kb}$ )
\end{abstract}

\section{Acknowledgements}

We thank Ilona Klamfuß and Karin Gerber for animal care.

\section{Funding}

The source of funding is the Fritz Thyssen Stiftung (http://www.fritz-thyssenstiftung.de, grant number: 10.12.2.146) and an intramural grant (FORUN 889018-2013). The funding agencies had no role in study design, data collection and analysis, decision to publish, or preparation of the manuscript.

\section{Availability of data and material}

All data generated and analysed during this study are included in this published article and its supplementary information file [Additional file 2: Primary data].

\section{Authors' contributions}

$\mathrm{RE}$ and $\mathrm{BMH}$ were involved in the experimental design. RE performed all experiments. $\mathrm{RE}$ and $\mathrm{BMH}$ wrote the manuscript and read and approved the final manuscript.

\section{Competing interests}

The authors declare that they have no competing interests. 


\section{Ethics approval}

All animal experiments were performed in accordance with the guidelines of the local animal use and care committee. This study was approved by the "Landesamt für Landwirtschaft, Lebensmittelsicherheit und Fischerei Mecklenburg-Vorpommern" (approval no. 7221.3-1.2-044/12). Animal housing was done by professional animal keepers. Animals were anesthetized using ketamine/xylazine prior to silika treatment and sacrified by cervical dislocation at the end of the study. All efforts were made to minimize suffering.

Received: 29 November 2016 Accepted: 15 February 2017

Published online: 13 March 2017

\section{References}

1. Taneja V. Arthritis susceptibility and the gut microbiome. FEBS Lett. 2014:588:4244-9.

2. Essouma M, Noubiap JJN. Is air pollution a risk factor for rheumatoid arthritis? J Inflamm (Lond). 2015;12. doi:10.1186/s12950-015-0092-1.

3. Lundström E, Källberg H, Alfredsson L, Klareskog L, Padyukov L. Geneenvironment interaction between the DRB1 shared epitope and smoking in the risk of anti-citrullinated protein antibody-positive rheumatoid arthritis: All alleles are important. Arthritis Rheum. 2009;60:1597-603.

4. Makrygiannakis D, Hermansson M, Ulfgren A-K, Nicholas AP, Zendman AJW, Eklund A, Grunewald J, Skold CM, Klareskog L, Catrina Al. Smoking increases peptidylarginine deiminase 2 enzyme expression in human lungs and increases citrullination in BAL cells. Ann Rheum Dis. 2008;67:1488-92.

5. Lugli EB, Correia RE, Fischer R, Lundberg K, Bracke KR, Montgomery AB, Kessler BM, Brusselle GG, Venables PJ. Expression of citrulline and homocitrulline residues in the lungs of non-smokers and smokers: implications for autoimmunity in rheumatoid arthritis. Arthritis Res Ther. 2015;17:9.

6. Lacher SE, Johnson C, Jessop F, Holian A, Migliaccio CT. Murine pulmonary inflammation model: a comparative study of anesthesia and instillation methods. Inhal Toxicol. 2010;22:77-83.

7. Seeuws S, Jacques P, Van Praet J, Drennan M, Coudenys J, Decruy T, Deschepper E, Lepescheux L, Pujuguet P, Oste L, Vandeghinste N, Brys R, Verbruggen $\mathrm{G}$, Elewaut D. A multiparameter approach to monitor disease activity in collagen-induced arthritis. Arthritis Res Ther. 2010;12:R160.

8. Valesini G, Gerardi MC, lannuccelli C, Pacucci VA, Pendolino M, Shoenfeld Y. Citrullination and autoimmunity. Autoimmun Rev. 2015;14:490-7.

9. Rabolli V, Lo Re S, Uwambayinema F, Yakoub Y, Lison D, Huaux F. Lung fibrosis induced by crystalline silica particles is uncoupled from lung inflammation in NMRI mice. Toxicol Lett. 2011;203:127-34.

10. Lee EH, Lee E, Kim HJ, Jang AS, Koh ES, Uh S-T, Kim YH, Park S-W, Park C-S. Overexpression of apolipoprotein A1 in the lung abrogates fibrosis in experimental silicosis. PLoS One. 2013;8:e55827.

11. Song L, Weng D, Dai W, Tang W, Chen S, Li C, Chen Y, Liu F, Chen J. Th17 can regulate silica-induced lung inflammation through an IL-1ß-dependent mechanism. J Cell Mol Med. 2014;18:1773-84.

12. Joshi GN, Knecht DA. Silica phagocytosis causes apoptosis and necrosis by different temporal and molecular pathways in alveolar macrophages. Apoptosis. 2013;18:271-85.

13. Thiele GM, Duryee MJ, Dusad A, Hunter CD, Lacy JP, Anderson DR, et al. Citrullinated mouse collagen administered to DBA/1J mice in the absence of adjuvant initiates arthritis. Int Immunopharmacol. 2012;13:424-31.

14. Lo Re S, Lecocq M, Uwambayinema F, Yakoub Y, Delos M, Demoulin J-B, et al. Platelet-derived growth factor-producing CD4+ Foxp3+ regulatory $T$ lymphocytes promote lung fibrosis. Am J Respir Crit Care Med. 2011;184:1270-81

15. Holmdahl R, Jansson L, Andersson M. Female sex hormones suppress development of collagen-induced arthritis in mice. Arthritis Rheum. 1986;29:1501-9.

16. Brunsberg U, Gustafsson K, Jansson L, Michaëlsson E, Ahrlund-Richter L, Pettersson S, Mattsson R, Holmdahl R. Expression of a transgenic class II Ab gene confers susceptibility to collagen-induced arthritis. Eur J Immunol. 1994;24:1698-702.

17. Holmdahl R, Bockermann R, Bäcklund J, Yamada H. The molecular pathogenesis of collagen-induced arthritis in mice-a model for rheumatoid arthritis. Ageing Res Rev. 2002;1:135-47.

18. Davis GS, Leslie KO, Hemenway DR. Silicosis in mice: effects of dose, time, and genetic strain. J Environ Pathol Toxicol Oncol. 1998;17:81-97.

19. Ohtsuka $Y$, Wang X-T, Saito J, Ishida T, Munakata M. Genetic linkage analysis of pulmonary fibrotic response to silica in mice. Eur Respir J. 2006;28:1013-19.

\section{Submit your next manuscript to BioMed Central and we will help you at every step:}

- We accept pre-submission inquiries

- Our selector tool helps you to find the most relevant journal

- We provide round the clock customer support

- Convenient online submission

- Thorough peer review

- Inclusion in PubMed and all major indexing services

- Maximum visibility for your research

Submit your manuscript at www.biomedcentral.com/submit 